\title{
3 Epistemic crossings of a marine biologist through gender encounters
}

\author{
By Bernadette P. Resurrección and Rebecca Elmhirst \\ In conversation with Maeve Nightingale
}

\section{Becoming a gender expert}

Gender mainstreaming today is almost an institutional pillar in development organisations, including in environmental conservation groups such as the International Union for the Conservation of Nature (IUCN). Conventional technical approaches in efforts to protect and conserve ecosystems and biodiversity have increasingly integrated social approaches, and gender mainstreaming ensures that gender issues are included. Apart from hiring dedicated gender specialists and professionals, environmental organisations sometimes assign their own technical personnel to conduct and carry out gender mainstreaming tasks. This has been the case with Maeve Nightingale at the IUCN Asia regional office who is a marine biologist by training, but who has become the regional office's gender focal point.

Some question whether a professional background is required to become a gender specialist. A useful way to tackle this question is how one acquires the knowledge to do this work effectively, which may not be the same for everyone. This chimes in with principles in feminist epistemology that posit knowledge as being situated and that there are multiple ways of knowing (Haraway, 1988; Trojer, 2014; Barbour, 2018). Additionally, this chapter will also explore how feminism and its ideas have been professionalised and like other professional sectors, its members may also seek ways to legitimate knowledge and expertise (Hoard, 2015; Kunz et al., 2019).

Maeve is senior and technical officer for coastal and marine programs at IUCN, which involves integrating ecosystem-based approaches with socio-ecological systems through a program implemented in 11 countries. She is also the regional gender focal point, integrating gender in all programs and building institutional capacity for gender analysis in the regional office as she works with senior program officers.

Maeve's particular route to becoming a gender expert was through field exposure and personal engagement with rural coastal communities for 22 years. It was not through formal training such as through the social sciences or gender studies. This aligns with findings from Bustelo, et al. (2016) that there is no agreed 
definition of the term 'gender expert', with no common criteria of what their work entails, and with no defined boundaries from where claims to intellectual authority may come.

Maeve: These last five years, I have devoted time to strengthening the resilience of coastal dependent communities in Asia. My role has been to integrate gender in the 11 countries where IUCN's Mangrove for the Future (MFF) operates, and as part of IUCN's gender and development policy. I have no formal background on gender, but only use my own observational skills having worked with coastal communities for 22 years, with the lens of women and men's roles and the balancing of societal relationships. So, when our regional director gave me the mandate to be the regional gender focal point for IUCN in Asia, I embarked on a three-year campaign to educate myself. Which meant that I talked to gender experts and mentors, taking their advice and reading a lot, so I could at least understand the language and adapt it to my own work and context.

I always had an interest in gender while working with coastal communities. I lived for eight years in these communities. Being a woman myself, the entry point was to sit and talk to women in particular. Without having any framework of analysis in mind, I was observing where the gaps were in terms of opportunities for women to have their voices expressed more publicly. And without knowing that that's called a 'gender gap', I was listening to women's stories juxtaposed with men's stories. In the fisheries sector, the teams I was part of were talking to the men. And I was talking to the women. And the fact that these two sets of exposure were so disjointed when they translated into development planning was quite striking to me. While working in this program, the regional director gave me the specific challenge to put things together in a sensible way and learn the 'gender' language. Honestly speaking, gender to me was an untouchable thing because I had no sufficient confidence to use the right terminology. This was quite daunting. It was like you had the experience and knowing what needs to be done but you didn't have the language! Until you had the language and the analytical framework to be able to express your observations, it felt that I was just on the doorstep of this process. I'm still not there yet, but I think I'm getting there.

Becky: So, is your professional identity that of a gender expert or a marine scientist? Are you becoming a gender expert?

Maeve: That will depend on who you ask that question to. Different people in my organisation will see me as the gender person, like the water program for example. But I see myself as a marine specialist. My confidence lies with marine resources management. But then having got this far in the gender integration work and being able to unpack gender in what we do, and to be able to bridge those two worlds, I would never close the door to being referred to as a gender professional. Since once you've opened it, you've opened it. And I think you will never walk backward. So, I wouldn't ever see myself dropping 
it since I really like it, and it allows me to raise the profile and concerns about marginalised groups in general.

Becky: When were the instances that you've found it not very helpful to identify yourself as somebody working on gender?

Maeve: I don't know if I do self-identify as a gender person in the first place [laughter]. That might be why I can't answer the question. But I do notice that within our own organisation as people kind of get to know that we're doing more and getting more practically experienced I'm now becoming known as the gender person. And sometimes, I feel like, 'Okay. That's nice and interesting.' But I don't want to subsume it under where I have more confidence in, which is in being a marine biologist. I don't mind that I've sort of become recognised as the gender person and not the marine person [laughter]. I think, in general, I don't think it hurts. I wonder sometimes though - I try not to forget what it was like not understanding anything about the language that goes with gender and development. I also don't think that I would stand up in an international conference and profess to be a gender person. I would explain my ideas on gender only on the basis of my own experiences.

Babette: But now you have a new lens. We gender folks working in environmental and natural resource management contexts usually need to learn about biophysical and technical conditions because gender and social issues are embedded in them. But that doesn't make us technical specialists, I'm afraid.

Maeve: And the lens is becoming more comfortable. But I know how it felt talking to gender people at the outset. And sometimes, it can feel that there is a barrier. Well, not a barrier, maybe a kind of hierarchy. There is a kind of supreme idea that either you are, or you are not, a gender expert.

Babette: Really? I thought the opposite [laughter]. I thought that it was we gender experts who are the ones most often edged out.

Maeve: I don't think it [the hierarchy] would be something that was easily confessed. But I think gender people who only know gender, who don't necessarily have an interdisciplinary background, their passion, their commitment is interesting and it's all cool. But there's also a bit of ... (voice trails off).

Babette: Arrogance?

Maeve: A little bit.

Babette: Maybe it's also because of our defensiveness? We need to protect the space? Years and years of being called 'flaky' by the sciences have probably made us defensive (laughter).

Maeve: It's a patch. It's a turf.

Babette: Oh, so it's territory.

Maeve: Yes, maybe it's that. The majority [of gender professionals] though want bridges to be built. But I remember an incident when we were producing training materials that link gender with the UN Convention on Biodiversity. We were all in a room for three or four days putting forward ideas and materials. On Day 4, something struck me: there's not a word for 'gender' in many languages. And I thought that was kind of interesting. There are sets of words, substitutes and also descriptions. But that wasn't really the point. So, 
I remember on Day 4 reiterating this comment. I said, 'If there's not a word for gender, shouldn't we unpack why there isn't a word for gender?' Meaning isn't there a reason why people do or don't understand gender simply by the fact there's not a word for it? Could that help us to grow an avenue of capacity development if we know why?

And there was a woman there who had worked for a major organisation, a very nice person, very knowledgeable, 'very gender', (laughter) and she said, 'We have fought long and hard to get gender on the table. It's in the policy dialogue. It doesn't matter that there's not a word for gender. This is not the issue. Gender is a fact. It is an established concept.' I was dumbfounded by her remark. I tried to reinterpret what I said that might have elicited that response. I was quite embarrassed, and I said, 'Oh, I'm sorry. I didn't mean to offend you.' I was just thinking about how we can deal with people not really knowing about gender since there's no word for it in some languages.

I was left completely in the dark. And even until today I feel it was a really intimidating experience. And I think that just reflects my own lack of confidence. It's probably not how gender people mean to project themselves. It's just my own lack of confidence in that environment. And none of the gender people batted an eyelid as to why this lady was kind of peeved. And I couldn't really get anybody to explain it to me. And I didn't want to belabour the whole thing, so I just let it go. It was fine. It was okay.

Babette: No, no, no. For me, that's not fine. It's silencing someone.

Maeve: In that workshop, I felt that I've had such limited experience. I think if you hang around gender people all the time, it becomes a language and a way of thinking, patterns of thinking that are common and comfortable. But if you impose it on environment language and ideas, the question arises on how we make the links. How do you put in gender into environment? I'm coming from an environment perspective, trying to find the entry points where it fits most comfortably and make the quickest sense to people.

This interesting episode may have indeed unleashed the defensiveness of gender experts towards questioning the very object of their work: that is, veracity of the existence of gender. As queer theorists and some feminists question the stability of 'gender', and the power dynamics that underlie its materialisation (Butler, 2004), sometimes through the very application of 'gender mainstreaming', gender experts may rightly need to reflect on their work and practice (Zalewski, 2010; Davids et al., 2014). Destabilising gender prompts a range of responses, and this gender expert may have experienced being pushed to the margins in the past and was not going to allow it to happen in that meeting. However, this explanation is insufficient and begs that we explore other elucidative avenues. One promising avenue is to explore how certain narratives and knowledge become 'expert truth', including, and not exempting, gender expertise.

Scholars who study professions have often observed how experts or professionals create boundaries to secure monopoly over their expertise and to protect its autonomy and authority. Claims to expertise empower professional groups 
to draw and defend boundaries that set conditions for inclusion and exclusion (Azocar \& Ferree, 2016; Liebrand, 2014). That said, other discursive elements also came into play in the episode just narrated and which served to silence. First, by invoking that gender is a 'fact', the speaker was mimicking the 'God trick' (Haraway, 1988), using the positivist argument where veracity, truth and authority are only based on what is observable, objective and measurable, or in short, it was an attempt to vest gender knowledge with the power of scientific truth. Ironically, feminist epistemology has long argued that knowledge is situated and not value-free. Second, science, technology and society (STS) scholars contend that expertise often operates as a network of power (Brady, 2018). In this view, stating 'gender as a fact' summons the historical assemblages of artefacts behind this statement such as gender indicators, gender analyses tools and checklists, academic and non-academic training curricula, publications, gender experts and feminist movements, donors, institutions all of which have been enrolled in the making of this networked field (van Eerdewijk \& Davids, 2014; Cornwall et al., 2007). Lave $(2011,2012)$ presents a similar case through her analysis of how a specific yet heavily contested type of geomorphological expertise on stream restoration came to be dominant. This expertise was legitimated through an assemblage of non-degree courses, publicity stunts, accreditation procedures, and social capital among trainees who later became well placed in US federal agencies. Gender expertise can also build from the accumulated performance of an actor network and its own assemblage of artefacts (e.g., mainstreaming tools, gender concepts and so on). That said, it is worth pointing out that gender expertise is also often unstable and comes into view when it is 'produced' relationally, through powerladen webs of political and social relationships which, for example, also defined the 'gender-is-a-fact' episode.

Maeve also expresses uneasiness with efforts to merge the social with the technical, and thus faces the difficulties of 'translating' the social or gender knowledge in an environmental action context.

Babette: We're coming from the other side. For instance, we try to look for how can gender equality be realised in natural resource management contexts. Let's say in agriculture: issues of labour, rights to land, may be the entry points.

Maeve: But those points are still sometimes a separate matter. They all make sense by themselves. But fitting them in, finding the flow between environment and gender issues, it feels a bit of a 'hit or miss' sometimes. And I find the same thing in gender trainings - most trainers take you into a framework, but that doesn't leave anybody with knowing what to do. Social and gender issues have a separate dialogue from environmental issues. They make sense on their own. How do we integrate these with the scientific aspects of the environment? Where is the commonality? And must there be?

Now I'm thinking of our gender equality tool at IUCN and how it actually doesn't agree with coastal issues from the scientific end. The tool is still predominantly social. 
We learn through trial and error which bits would work and which bits are more powerful, and how to facilitate those which are going to give you the quickest insight and exchange among people.

In a related chapter in this book, Margreet Zwarteveen and Seema Kulkarni discuss how it may be fruitful to recognise the plurality of knowledges rather than attempting to integrate them. It means creating room for different ways of knowing and different versions of reality to co-exist. Knowledge acquired through experience - or embodied knowledge - demonstrates the plurality of knowledges.

\section{Embodied knowledge}

From her experiences working with coastal communities, Maeve has observed mismatches between program goals and gender realities. She encounters migration, the loss of land, personal insecurity, and gender-based violence that are unfortunately beyond the purview of her organisation's conservation goals and livelihood programs. There is also the issue of short project durations that may be unable to effect substantial change and Maeve is acutely aware that transformative changes take time. She nevertheless takes note of the small changes in these communities she spends time in, which in the long term, she believes may be incremental.

Maeve: I have witnessed small changes along the way: women become more confident to speak and represent themselves. They're also able to talk about domestic violence. They also try to find solutions jointly for issues that affect them, whereas otherwise they would have to suffer individually. It might be hard to imagine but on a three-year program basis, I think you could start seeing change, and certainly better representation of women outside their own households within a small part of the village. The most striking would be how readily women are able to express issues that they're experiencing, secretly, in confidence sharing with other women with whom they may never have talked about these things before.

Field experiences and close interactions with women can open new avenues of knowledge. Conventional scientific epistemologies cannot account for women's experiences and sometimes do not consider them as legitimate knowledge, as scientific knowledge is traditionally premised on objectivity and rationality. The dualistic ontology of Western knowledge traced back to the ancient philosophical works of Aristotle and Plato recognises reason and experience as being diametrically opposed. In turn, the feminist critique to science has long argued for the reconstruction of knowledge itself, alluding to other equally legitimate forms of knowledge, and more recently attempts to pluralise knowledge (Mukhtarov \& Gerlak, 2014).

The feminist adage 'the personal is political', puts forth the idea that personal experiences of women are a source of important knowledge, and that they can be 
understood socio-culturally and are politically contextual largely because they unpack situations of inequality. 'Women's problems' - such as domestic violence - have come to be seen as widely structural, and therefore political (Barbour, 2018), thus meriting institutional attention and redress. Knowledge embodied in experience, feminists argue, is a legitimate form of knowledge. Gender experts in technical environment organisations who recognise the importance and relevance of this knowledge may often face the prospect of their findings not being given sufficient importance.

Babette: How then do you integrate gender with your coastal management projects on the ground and with your colleagues?

Maeve: I think that you shouldn't start out jumping off with 'gender' with people since they'll immediately think 'women'. It is better to start by talking about and understanding empowerment and disempowerment and what causes them among different groups who are commonly marginalised and experiencing disempowerment and the roots of that. Then one should go to how their marginalisation is being affected by their being male or female. So it's like looking at that minority group angle.

With colleagues, I feel that if you take them (our whole organisation is made up natural scientists), to 'let's look at how you can integrate a gender perspective', they'll only get as far as pointing out the women's roles, and perhaps the possibility of doing some women's projects. By doing this, the full analysis of gender inequality will be lost. For example, we saw in Laos that there is legal recognition for equal institutional positions for women and men, yet we see that at the community level there are predominantly male leaders. Why is that? So unpacking the causes of that is helpful, which helps us to think: what can our little project do in three years that might lead to an incremental stage towards enabling the leadership capacity of women and leveraging opportunities for women to have a stronger voice? So they think ahh that means that when we have our consultations, we can address that gap. Then they think - but women can't talk, they have caring tasks and can't come - so what can our project do to address that? So after one day of this they went away feeling empowered and looking at their project in a different light, which was not prescriptive, and they felt capacitated to take on-board the thinking about inclusive development. And that's the key, right? It's being development practitioners and thinking holistically.

Babette: Considering that you've had 22 years of living with coastal communities, how much does planning really lead to change? As we know in real life, changes are usually unplanned, and life is much more complex, and changes actually come in unintended ways. So, will planning change really matter in the long run, you think?

Maeve: I think if we're talking at a project scale of three to five years, with some concrete objectives, and positioned in the context of an overall theory of change, I think planning definitely has a place, it can influence change. And if we're talking about specifically gender integration in some of the 
natural resource management ecosystems-focused projects, without planning concretely for social engagement, social empowerment, it won't happen by magic. So 'not' planning has an effect. You will get perhaps fewer rich results, definitely less sustainable results. Planning for short-term changes within a project context, and within the larger, longer term theory of change that you're working with in that context definitely can improve results or create positive change for people. Thinking about the gender context again, if we apply gender inclusion in our own processes for implementing projects, in project planning and design, already we will provide completely different outcomes. In communities, there are a few avenues for creating strong, empowered relationships.

Becky: Can you tell us about some examples?

Maeve: We went to an island called Nijhum Dwip, a southern island in the Bay of Bengal in Bangladesh. It's the most remote island you can get to from Dhaka and it's known as the quiet island. It was only actually created in the last 50 years and government programs resettled displaced people on this island. So, this community hasn't evolved into a socially cohesive community. People were resettled there generally because they have not been able to stay on their original homeland and many of them have weak land tenure or security. On top of this, women have very, very restricted mobility and this is having a direct impact on their opportunities to make change at the household and community levels, almost a complete invisibility of women's voice in societal decisions.

All of the gender tools that people talked to me about in the past suddenly made perfect sense. First of all, just create dialogues around basic human rights and build confidence among women facing the same issues within their homes who are not able to voice them, talking about the conditions that they live in and slowly coming to realize that those are not conditions that they necessarily need to accept or be expected to accept. We have a five-year project in the island that focuses on fisheries and governance of marine protected areas, but without us taking a really considered effort to have longterm 15-year commitment to work with those communities, we're not going to see much change.

Becky: We've heard this conversation with others around how it is sometimes almost better to engage with these communities with a sort of broader view on social transformation rather than just using the gender as your entry point. And your example kind of gives suggestions to why the gender word is necessary in a very clear way. But I'm guessing that in other places where you've worked that perhaps it isn't quite so obvious. So, in terms of planning for changes are you also not focusing on bigger forms of empowerment other than gender equality? What's your thinking on that?

Maeve: These women on the island are severely constrained in their ability to broaden their opportunities. Once they start to actually increase their latitude, they are set apart socially and stigmatised. And in that sense, it becomes much more counterproductive to plan for change given those conditions, but 
other entry points might be possible. I guess that's what change being so complex means. So, we aim to create some sort of safe space. What these women are experiencing - domestic violence - is just laughed off and continues to be passed down by generation and completely explainable by these ladies. And it's not just one or two, it's across everybody we interviewed. When at 13 if you're not married then you become a burden. Women speak about their own daughters being burdens. They talk to us about these issues despite being strangers. They would say, 'You can understand why we get hit - when we haven't got food on the table and there's no petty cash for cigarettes, you can understand why they're annoyed.' They also said that 'the water level has raised, and we would need to lift our saris to get to the tube well and we can't do that. It's rainy season. If we keep our saris down, we are then going to have to sit in the one and only sari we have which will be completely wet.' So, they can't fetch water. If they don't fetch water, nobody at home has water, right? They discuss these dilemmas as a group and there would be solutions that they find. These are things that you can find solutions for if you work together. But if you're on your own suffering individually it's hard to imagine what on earth is going to change that scenario.

Becky: How do you reconcile your technical background and your community work?

Maeve: Okay, you're referring to being a natural scientist turning into a social scientist, right? In teaching integrated coastal management at the Asian Institute of Technology, for example, we teach all the natural science part such as the ecosystem structuring function. Then we also teach the social science part of it which is understanding the communities you're working with and providing them with principles and tools to do that, which most of the foresters and the fisheries graduates almost have never come across. Science is maybe perceived to be technically complicated, and social science is perceived as the soft science, so to speak. But to me, what's more important is where the meeting place is. And in our organisation, we deal a lot with governance such as the protection of biodiversity through good governance. And in unpacking the governance part of it we come to understand social equality issues.

I remember in one field situation, our project manager requested that we de-brief him on what we found out from our gender study. After listening to our accounts, he said, 'Okay, that's nice. So, you've turned up the fact that there's domestic violence issues, and you've turned up the fact that women have limited access to education, and that child marriage is a problem, and mobility. But we don't want to get too waylaid by that. We want to focus on the governance of marine protected area.' When he said that I and my companions were aghast. I think he missed the point. We need to understand how communities can change their circumstances, right? All the rest might follow.

Maeve's stories of her immersion in coastal communities reveals the workings and importance of embodied knowledge. To effectively engage in pluralising knowledge, Mukhtarov and Gerlak (2014) say that policy professionals should be 
able to tell compelling stories rather than relying on the 'bloodless discourse of science and expertise'. Her encounters with local people in the coastal areas offer her 'practical knowledge' derived from her first-hand observation of the social contexts within which coastal people use their resources. 'Knowing-throughpractice implies that knowledge is specific to a particular situation and, therefore, tied to specific communities. In this way, practice is not intended to reflect "best practices" or more cookbook approaches. Rather, it is through interaction that people make sense of reality, negotiating the meaning they give to their surroundings and their actions.' (Brugnach \& Ingram, 2011: 52).

\section{To conclude}

We learn from Maeve that the route to the gender profession can be through one's keen interest and immersion in the daily lives of people in communities. Immersions in communities or 'life on the ground' leads to insights and reflections that can enlighten action and practice.

However, acquiring new knowledge, such as gender knowledge, can be challenged by its own vanguards as its professionalisation like in all other sciences evolves its own forms of exclusions and inclusions.

From the examples presented in this chapter, we have seen how professionals may contribute to the building of silos between and within their sciences through networks and other artefacts. There is need to respect the different sciences, their different and multiple ways of knowing, since erecting professional walls serves only to exclude and slow down the success of development in more holistic and inclusive terms.

\section{References}

Azocar, M. J., \& Ferree, M. M. (2016). Engendering the sociology of expertise. Sociology Compass, 10(12), 1079-1089. https://doi.org/10.1111/soc4.12438

Barbour, K. (2018). Embodied ways of knowing: Revisiting feminist epistemology. In L. Mansfield, J. Caudwell, B. Wheaton, \& B. Watson (Eds.), The Palgrave Handbook of Feminism and Sport, Leisure and Physical Education (pp. 209-226). Palgrave Macmillan UK. https://doi.org/10.1057/978-1-137-53318-0_14

Brady, J. (2018). Toward a critical, feminist sociology of expertise. Journal of Professions and Organization, 5(2), 123-138. https://doi.org/10.1093/jpo/joy004

Brugnach, M., \& Ingram, H. (2011). Rethinking the role of humans in water management: Toward a new model of decision-making. In Water, Cultural Diversity, and Global Environmental Change (pp. 49-64). Springer Netherlands.

Bustelo, M., Ferguson, L., \& Forest, M. (Eds.) (2016). The Politics of Feminist Knowledge Transfer: Gender Training and Gender Expertise. Palgrave Macmillan.

Butler, J. (2004). Undoing Gender. Routledge.

Cornwall, A., Harrison, E., \& Whitehead, A. (2007). Gender myths and feminist fables: The struggle for interpretive power in gender and development. Development and Change, 38(1), 1-20. https://doi.org/10.1111/j.1467-7660.2007.00400.x 
Davids, T., van Driel, F., \& Parren, F. (2014). Feminist change revisited: Gender mainstreaming as slow revolution. Journal of International Development, 26(3), 396408. https://doi.org/10.1002/jid.2945

Haraway, D. (1988). Situated knowledges: The science question in feminism and the privilege of partial perspective. Feminist Studies, 14(3), 579-599.

Hoard, S. (2015). Gender Expertise in Public Policy towards a Theory of Policy Success. Palgrave Macmillan.

Kunz, R., Prügl, E., \& Thompson, H. (2019). Gender expertise in global governance: Contesting the boundaries of a field. European Journal of Politics and Gender, 2(1), 23-40. https://doi.org/10.1332/251510819X15471289106112

Lave, R. (2011). Circulating knowledge, constructing expertise. In M. Goldman, P. Nadasdy, \& M. Turner (Eds.), Knowing Nature: Conversations at the Intersection of Political Ecology and Science Studies (pp. 363-279). University of Chicago Press.

Lave, R. (2012). Bridging political ecology and STS: A field analysis of the Rosgen Wars. Annals of the Association of American Geographers, 102(2), 366-382. https://doi.org /10.1080/00045608.2011.641884

Liebrand, J. (2014). Masculinities among Irrigation Engineers and Water Professionals in Nepal (Wageningen UR Library) [Wageningen University]. http://edepot.wur. $\mathrm{nl} / 321002$

Mukhtarov, F., \& Gerlak, A. K. (2014). Epistemic forms of integrated water resources management: Towards knowledge versatility. Policy Sciences, 47(2), 101-120. https:// doi.org/10.1007/s11077-013-9193-y

Trojer, L. (2014). Gender research as knowledge resource in technology and engineering. In W. Ernst \& I. Horwath (Eds.), Gender in Science and Technology: Interdisciplinary Approaches (p. 262). Transcript-Verl.

van Eerdewijk, A., \& Davids, T. (2014). Escaping the Mythical Beast: Gender mainstreaming reconceptualised. Journal of International Development, 26(3), 303316. https://doi.org/10.1002/jid.2947

Zalewski, M. (2010). 'I don't even know what gender is': A discussion of the connections between gender, gender mainstreaming and feminist theory. Review of International Studies, 36(1), 3-27. 